\title{
A Novel Hybrid Anti-islanding Detection Method for Three-phase Grid Connected Utility Interactive Inverter of a PMSG-based Wind Power Generation
}

\author{
Sung-Wook Kang ${ }^{1}$ and Kyeong-Hwa Kim ${ }^{2}$ \\ ${ }^{1,2}$ Department of Electrical and Information Engineering \\ Seoul National University of Science and Technology \\ 232 Gongneung-ro, Nowon-gu, Seoul, 139-743, Korea \\ ${ }^{2}$ Corresponding Author \\ k2h1@seoultech.ac.kr
}

\begin{abstract}
Islanding in a gird connected inverter of wind power generation system may give a bad effect on equipments or yield safety hazards on grid so it should be detected rapidly and exactly. Passive methods are simple to detect islanding by monitoring parameters of system but it has non detection zone (NDZ). Active methods are more effective to detect islanding by injecting small disturbance into output of utility interactive inverter. This paper proposes a novel hybrid anti-islanding detection method, which combines the conventional passive over/under voltage and over/under frequency (OUV-OUF) method with a new active harmonic injection method. In the proposed scheme, the active methods can be used effectively to overcome the problem caused by the NDZ. When NDZ does not exist, the passive methods can detect the islanding rapidly. The effectiveness of the proposed scheme is proved through comparative simulation results.
\end{abstract}

Keywords: Harmonic injection, Hybrid anti-islanding detection, NDZ, PMSG, Three-phase utility interactive inverter, Wind power generation

\section{Introduction}

A thermal power generation using fossil fuels is one of the main reasons for environmental pollution and global warming because it emits greenhouse gas. For that reason, global wind power capacity has been increased rapidly during past years and lots of control methods have been developed for wind turbine. In the past, constant speed type induction generators have been normally used for a wind power generation system because of the advantages such as low cost and robustness. However, they have some drawbacks such as loud noise, increased mechanical losses and the demand for bulky gear box. Nowadays, a permanent magnet synchronous generator (PMSG) which overcomes those limitations based on a back-to-back converter is generally used for a wind power generation system. The back-to-back converter consists of a machine side converter (MSC) and a grid side converter (GSC) which is often referred as a utility interactive inverter. The back-to-back converter converts the generator output power in variable voltage and variable frequency to the fixed voltage and frequency of grid [1-4].

In order to operate the distributed generation (DG) system such as the wind power system into grid, the inverter has to be complied with the grid requirements like IEEE Std. 929-2000 
and 1547 [5-6]. These grid regulations require the power quality of DG such as the normal voltage and frequency operation range, waveform distortion, power factor, and voltage flicker as well as the protection methods like anti-islanding. Islanding represents a condition in which the utility interactive inverter continues to operate even though the grid is isolated from the inverter and local loads. Islanding may cause safety hazard to human and give bad effects on electrical equipments. Therefore, it should be detected rapidly and reliably in order that the utility interactive inverter could cease to supply the power to grid immediately. The overall configuration of a wind power generation system is shown in Figure 1.

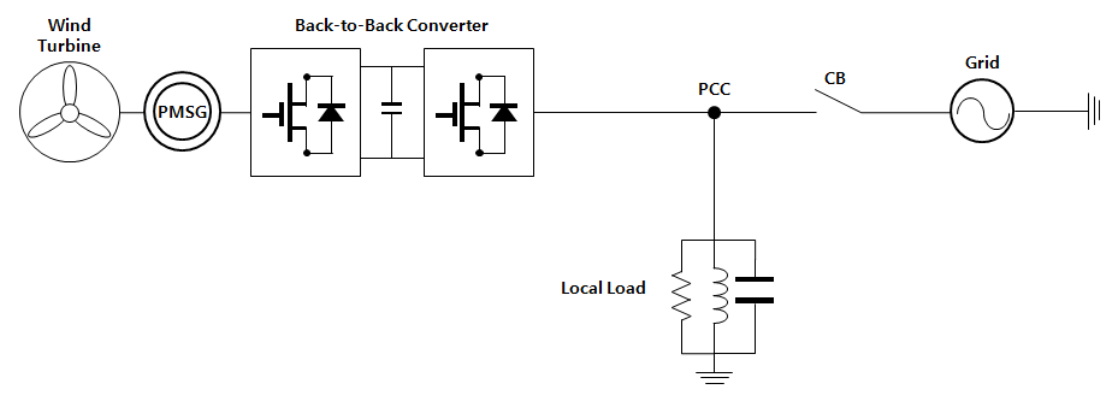

Figure 1. Configuration of a Wind Power Generation System

For a wind power generation system based on the PMSG, this paper proposes a novel hybrid anti-islanding method combined with the conventional passive over/under voltage and over/under frequency detection method and a new active harmonic injection method using Fourier transform. By using the proposed hybrid anti-islanding method, the occurrence of islanding can be detected rapidly and reliably irrespective of the existence of non-detection zone (NDZ). The effectiveness of the proposed scheme is proved through comparative simulation results.

\section{Passive Method and NDZ}

Anti-islanding methods are largely classified as the passive and active methods. To detect the islanding, the passive methods such as the over/under voltage and over/under frequency (OUV-OUF) method observe the change in the amplitude of voltage, frequency, phase, or harmonics under the islanding condition. These typical passive methods are classified into [7]

- Phase Monitoring Method

- Voltage Harmonic Monitoring Method

- Over/Under Voltage and Over/Under Frequency Method.

Phase monitoring method uses the phase difference before and after the islanding occurs. Voltage harmonic monitoring method monitors the voltage harmonic distortion to detect islanding. It is not easy to detect islanding using this scheme when the voltage harmonic distortion is not enough. OUV-OUF method monitors the grid voltage and frequency because these parameters can be changed after the grid is disconnected. When the grid connected, the power relation at local load between the utility interactive inverter and grid is shown in Figure 2. 


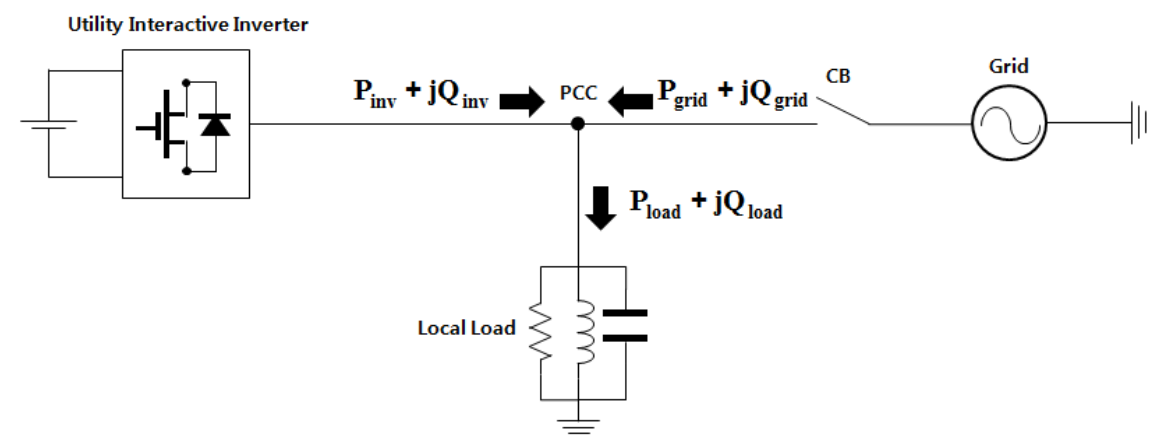

Figure 2. Configuration of the Utility Interactive Inverter with Local Loads when the Grid is Connected

In grid connected operation, the active and reactive powers on PCC load $P_{\text {load }}$ and $Q_{\text {load }}$ are expressed as

$$
\begin{gathered}
P_{\text {load }}=P_{\text {inv }}+P_{\text {grid }} \\
Q_{\text {load }}=Q_{i n v}+Q_{\text {grid }}
\end{gathered}
$$

where $P_{i n v}$ and $Q_{i n v}$ are the output power supplied by the utility interactive inverter, respectively, and $P_{\text {grid }}$ and $Q_{\text {grid }}$ are the power supplied from grid, respectively. When the grid disconnected, the configuration of the utility interactive inverter with local loads is shown in Figure 3.

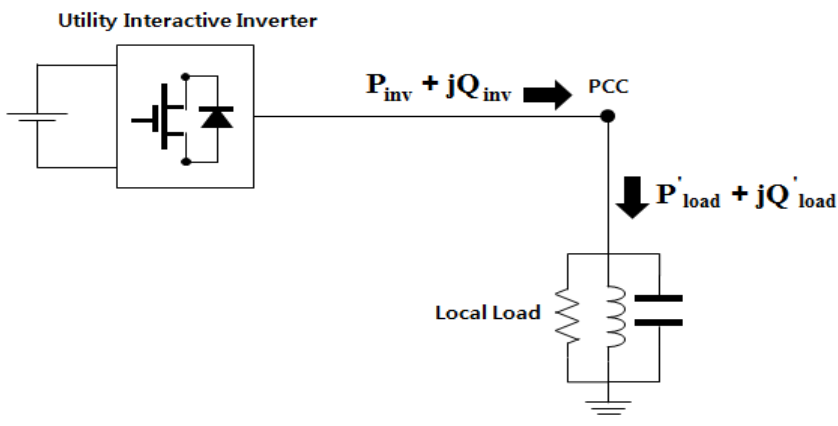

Figure 3. Configuration of the Utility Interactive Inverter with Local Loads when the Grid is Disconnected

After the grid is disconnected, local load on PCC is supplied only from inverter. In this condition, the active and reactive powers on load $P_{\text {load }}^{\prime}$ and $Q_{\text {load }}^{\prime}$ are represented as

$$
\begin{gathered}
P_{\text {load }}^{\prime}=P_{i n v}=\frac{\left(V^{\prime}\right)^{2}}{R} \\
Q_{i n v}^{\prime}=Q_{i n v}=\left(\frac{1}{\omega^{\prime} L}-\omega^{\prime} C\right)\left(V^{\prime}\right)^{2} .
\end{gathered}
$$


where $V^{\prime}$ is the changed load voltage, $\omega^{\prime}$ is the changed load angular frequency, and $L$ and $C$ are the load inductance and load capacitance under islanding condition. As is shown in (1)-(4), there is the power mismatch when the islanding occurs, which affects the voltage and frequency on load. Because active power on load becomes the same with the active output power supplied by inverter, $V^{\prime}$ is changed proportionally to $P_{i n v}$ as follows:

$$
V^{\prime}=V \sqrt{\frac{P_{\text {load }}^{\prime}}{P_{\text {load }}}} .
$$

From (4), the changed load angular frequency $\omega^{\prime}$ can be obtained as follows:

$$
\omega^{\prime}=\frac{-\frac{Q_{\text {load }}^{\prime}}{C\left(V^{\prime}\right)^{2}}+\sqrt{\frac{Q_{\text {load }}^{\prime}}{C\left(V^{\prime}\right)^{2}}+\frac{4}{L C}}}{2} .
$$

From this equation, it is clear that the load frequency is influenced by the reactive power as well as by the amplitude of load voltage. Abnormal parameter ranges are specified in grid requirements to protect DG system. Table 1 shows the clearing times with respect to the abnormal voltage and frequency ranges in accordance with IEEE Std. 1547 when DG has the power less than 30 [kW].

Table 1. Clearing Times with Respect to the Abnormal Voltage and Frequency Ranges

\begin{tabular}{|c|c|}
\hline Voltage Range $(\%)$ & $\begin{array}{c}\text { Clearing Time } \\
(\mathrm{s})\end{array}$ \\
\hline $\mathrm{V}<50$ & 0.16 \\
\hline $50 \leq \mathrm{V}<88$ & 2 \\
\hline $110<\mathrm{V}<120$ & 1 \\
\hline $120 \leq \mathrm{V}$ & 0.16 \\
\hline \hline $\begin{array}{c}\text { frequency Range } \\
(\mathrm{Hz})\end{array}$ & $\begin{array}{c}\text { Clearing Time } \\
(\mathrm{s})\end{array}$ \\
\hline $\mathrm{f}<59.3$ & 0.16 \\
\hline $\mathrm{f}>60.5$ & 0.16 \\
\hline
\end{tabular}

If the magnitude of voltage or frequency is within these abnormal ranges, it can be considered as islanding condition and the inverter should be stopped within clearing time. Figure 4 shows the conventional passive OUV-OUF detection method for islanding. If the voltage or frequency value is beyond the NDZ, the time $T$ is increased. As soon as this time $T$ is larger than the setting time $T$ - $C$, the controller eventually confirms the occurrence of islanding, which makes the inverter to stop supplying power to the load. However, even if the islanding occurs, these parameters could exist within the permitted range, which makes the islanding detection impossible. In this case, this permitted range is often called as NDZ. Figure 5 shows NDZ, which seriously influences on the islanding detection in the passive methods. 


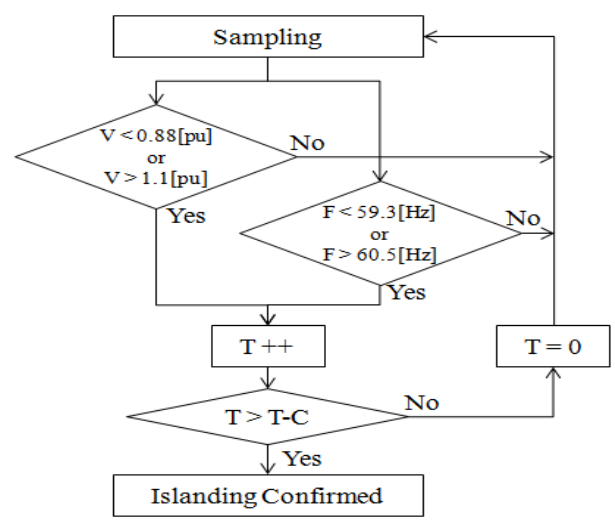

Figure 4. Conventional Passive OUV-OUF Detection Method

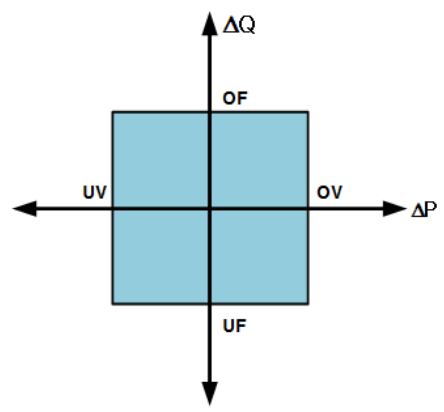

Figure 5. Non-Detection Zone

\section{Proposed Hybrid Anti-Islanding Method}

Although the passive methods are simple to implement, they inherently have NDZ, which makes it impossible to detect the islanding under specific operating conditions [8]. On the other hand, the active methods inject small disturbances such as the distortion in current waveform or harmonics into the output of utility interactive inverter to detect the islanding. Since the active methods reduce NDZ significantly, they can detect the islanding much more reliably as compared with the passive methods. For this reason, the active methods have been studied widely in a utility interactive inverter to improve the reliability in detection. Typical active methods are classified as follows:

- Active Frequency Drift [9-10]

- Reactive Power Variation [11-12]

- Harmonic Injection [13-16].

The active frequency drift method injects a perturbation to current which makes the inverter drift the frequency under the islanding condition. The reactive power variation method injects a reactive current into the output of inverter to detect the change in frequency when the islanding occurs. The harmonic injection method is same as the voltage harmonic monitoring method, but this method intentionally injects a specific harmonic into the output current. Generally, the active methods have the drawbacks such as a high total harmonic distortion (THD) and distorted current waveform during 
the normal operating condition. Harmonic injection method using the seventh harmonic has been proposed. To detect islanding, this method uses the $d q$-transformation rotating at the seven times synchronous frequency [16]. However, this detected seventh harmonic voltage is not easy to compare with the specified threshold value.

The proposed novel harmonic injection method injects the seventh-order harmonic component into the output current to detect the islanding by monitoring the harmonic component. Figure 6 shows the proposed hybrid anti-islanding scheme for a grid connected wind power generation system. Figure 7 shows the proposed harmonic detection algorithm using the seventh-order harmonic.

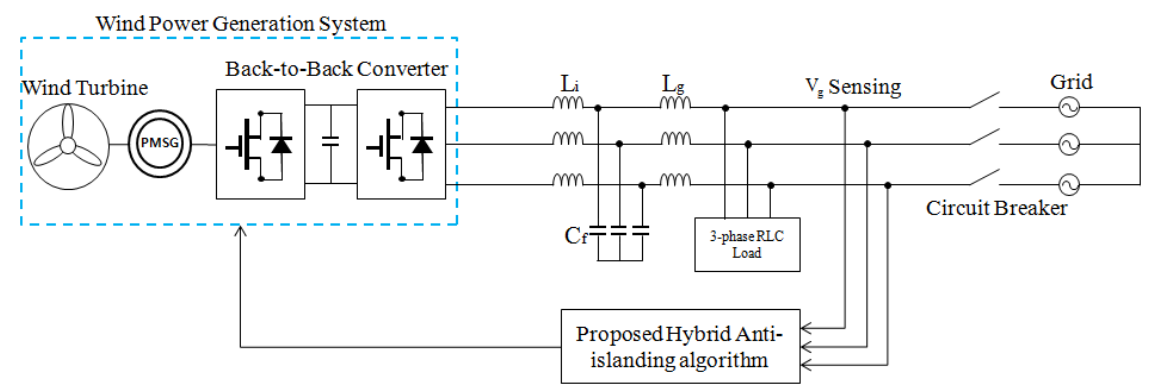
Figure 6. The Proposed Hybrid Anti-Islanding Scheme for a Grid
Connected Wind Power Generation System

The measured three-phase voltages $V_{g(7 t h)}$ at PCC are processed through the second order band-pass filter (BPF) with the center frequency of $420[\mathrm{~Hz}]$ and bandwidth of 20 $[\mathrm{Hz}]$. From the extracted seventh harmonic components of the three-phase voltages, the seventh harmonic value is calculated using the Fourier transform and are expressed as

$$
\begin{gathered}
\left|V_{g(7 t h)}\right|=\sqrt{a_{n}^{2}+b_{n}^{2}} \\
a_{n}=\frac{7}{T} \int_{0}^{\frac{T}{7}} V_{g(7 t h)} \cos (7 \omega t) d t \\
b_{n}=\frac{7}{T} \int_{0}^{\frac{T}{7}} V_{g(7 t h)} \sin (7 \omega t) d t .
\end{gathered}
$$

where $\left|V_{g(7 t h)}\right|$ is the magnitude of the calculated seventh-order harmonic component. In the proposed scheme, only a seventh of fundamental periodic data is used for the harmonic calculation to reduce the calculation time. Using the obtained three-phase harmonic values $V_{a}{ }^{7 t h}, V_{b}{ }^{7 t h}$, and $V_{c}^{7 t h}$, the maximum value is taken as $V_{\max }{ }^{7 \text { th }}$. When this maximum value $V_{\max }{ }^{7 \text { th }}$ is larger than the specified threshold level $V_{\text {threshold }}^{7 \text { th }}$, the time $T$ is increased. If $T$ is larger than $T$ - $C$, the islanding is confirmed. 


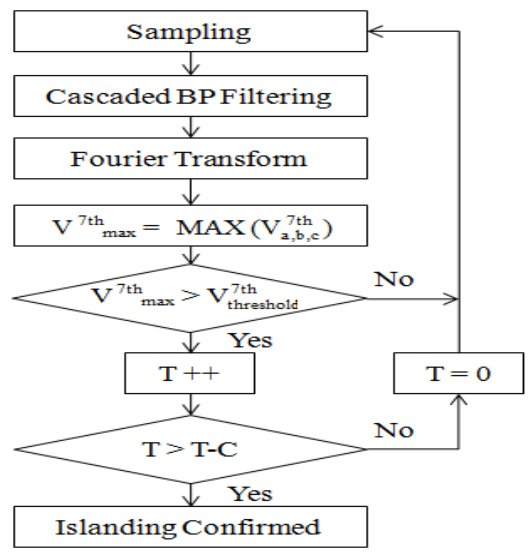

Figure 7. The Proposed Harmonic Detection Algorithm

Whereas the passive methods are easy and fast to detect the islanding, the active methods can detect the islanding very reliably. To decrease NDZ and detection time, the proposed scheme is achieved by combining the conventional passive OUV-OUF method with the active harmonic injection method. By using this proposed hybrid scheme, the islanding can be detected rapidly as well as reliably. Figure 8 shows the proposed hybrid anti-islanding method.

\section{Simulation Results}

To verify the effectiveness of the proposed scheme, the comparative simulations are performed. In a PMSG-based wind power generation system, the output power of 2 $[\mathrm{kW}]$ and $3[\mathrm{~kW}]$ are considered. According to IEEE Std. 1547, the power at RLC load is selected as $3[\mathrm{~kW}]$ and the quality factor is set to one. For the conventional passive method, the permissible voltage range in the inverter is selected between 0.88 [p.u] and 1.1[p.u], and frequency range between $59.3[\mathrm{~Hz}]$ and $60.5[\mathrm{~Hz}]$. The islanding due to the grid fault is assumed to occur at 0.3 [s] and T-C is set to 50 [ms].

When the power variation at load is small after the islanding occurs, the conventional passive OUV-OUF method cannot detect the islanding because the change in voltage and frequency at load is within the NDZ. The voltage and frequency waveforms at PCC under the generator output power of $3[\mathrm{~kW}]$ are shown in Figure 9. Even in this case, the proposed harmonic injection method can detect the islanding reliably regardless of the existence of NDZ since the seventh harmonic component is well observed in the grid voltage. In this case, the computed harmonics through the signal processing and harmonic calculation are shown in Figure 10. As shown in Figure 10, the seventh harmonic components $V_{a 7 t h}, V_{b 7 t h}$, and $V_{c 7 t h}$ are increased after the islanding occurs at $0.3[\mathrm{~s}]$. By monitoring these values, the islanding is confirmed and the utility interactive inverter stops operating at 0.378 [s]. Voltage and current waveforms in $a$-phase under this case are shown in Figure 11. 


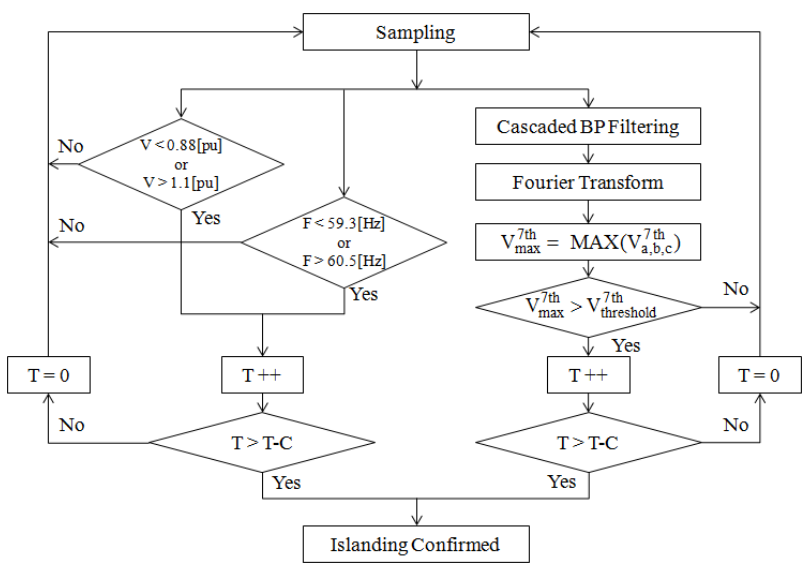

Figure 8. The Proposed Hybrid Anti-Islanding Method

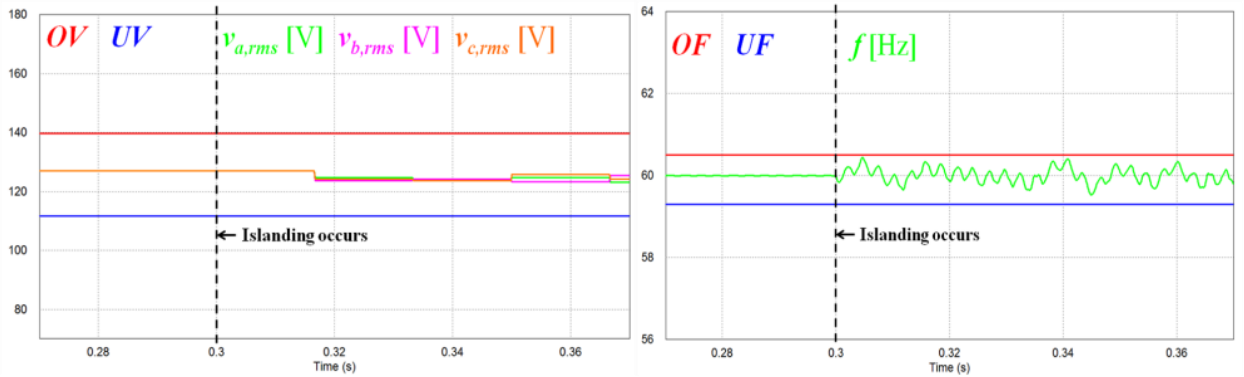

Figure 9. Voltage and Frequency Variation at PCC after the Islanding at $\mathbf{0 . 3}$ [s] under the Generator Output Power of 3 [kW]

On the other hand, when the power variation at load is large after the islanding occurs at 0.3 [s], the conventional passive OUV-OUF method can detect the islanding rapidly because the voltage values $V_{a, r m s}, V_{b, r m s}$, and $V_{c, r m s}$ escape the specified NDZ bounds immediately. Such a large power variation at load happens at the generator output power is $2[\mathrm{~kW}]$ and the voltage and frequency waveforms at PCC in this case are shown in Figure 12, and the voltage and current waveforms in $a$-phase under the generator output power of $2[\mathrm{~kW}]$ are shown in Figure 13. Since the passive method is basically fast, it can be an effective way of detecting the islanding for this condition. As shown in Figure 13, the islanding is confirmed at 0.366 [s]. For this condition, the passive method can detect the islanding within 0.366 [s] in our simulation. 


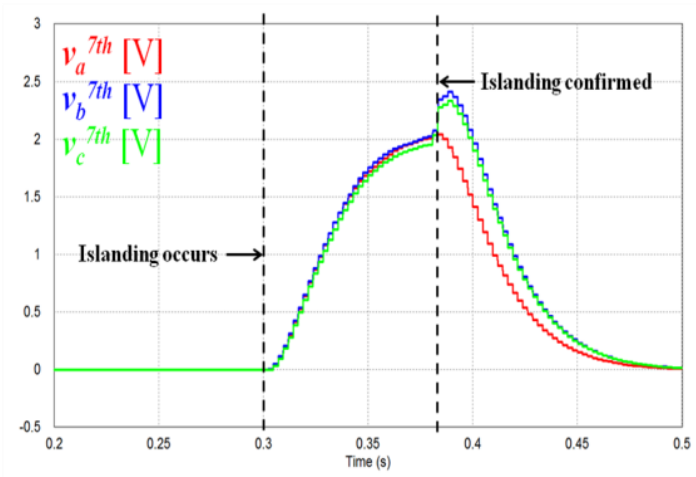

Figure 10. Harmonic Characteristics of Three-Phase Voltages at PCC after the Islanding at 0.3 [s] under the Generator Output Power of 3 [kW]

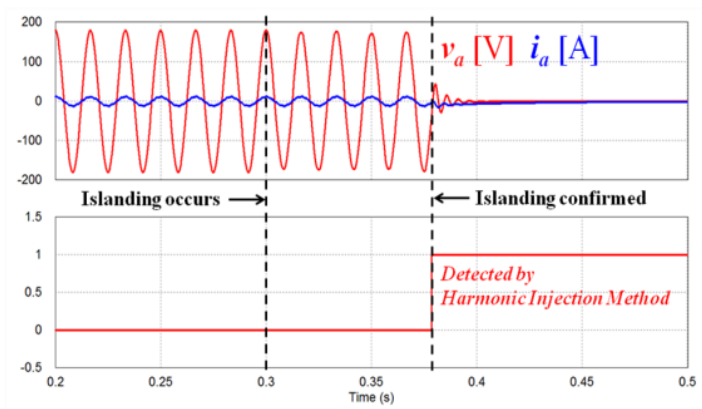

Figure 11. Voltage and Current Waveforms in A-Phase of GSC after the Islanding at $\mathbf{0 . 3}$ [s] under the Generator Output Power of 3 [kW]

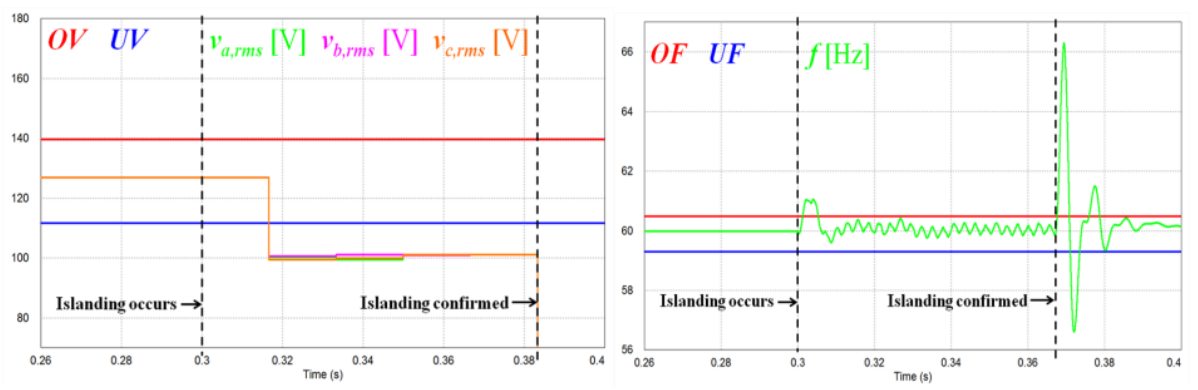

Figure 12. Voltage and Frequency Variation at PCC after the Islanding at 0.3 [s] under the Generator Output Power of 2 [kW] 


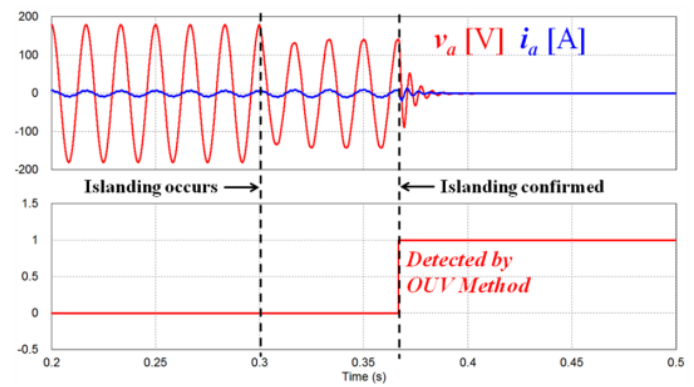

\section{Figure 13. Voltage and Current Waveforms in A-Phase of GSC after the Islanding at 0.3 [s] under the Generator Output Power of 2 [kW]}

\section{Conclusions}

This paper proposes a novel hybrid anti-islanding method to improve the reliability of a PMSG-based wind power generation system. Since the islanding causes serious risks on electrical equipments and human, it has been an important issue in DG systems. While the conventional passive methods are generally simple and rapid to detect the islanding, they have the drawback caused by NDZ. To overcome the limitation due to NDZ, active methods have been introduced. By adopting these methods, the islanding can be detected reliably through the injection of disturbance. However, these schemes have some disadvantages like the high THD. The proposed scheme is achieved by combining the conventional passive OUV-OUF method which reduces the detection time with the active harmonic injection method which overcomes NDZ. When the voltage or frequency escapes the NDZ bounds after the islanding, the passive OUVOUF method can detect the islanding rapidly. Even for the condition that the passive method cannot detect the islanding, the proposed scheme can detect the islanding reliably regardless of the NDZ. The effectiveness of the proposed scheme has been proved through the comparative simulations for different operating conditions.

\section{Acknowledgements}

This research was supported by Basic Science Research Program through the National Research Foundation of Korea(NRF) funded by the Ministry of Education(NRF-2012R1A1A2042759).

\section{References}

[1] T. H. Truong and K. S. Ro, "Improvement of LVRT Characteristic of SCIG Wind Turbine System by Incorporating PMSG”, Int. J. EIC, vol. 3, no. 3, (2012).

[2] J. H. Lee, G. L. Park, E. H. Kim, Y. C. Kim and I. W. Lee, "Wind Speed Modeling based on Artificial Neural Networks for Jeju Area", Int. J. of Control and Automation, vol. 5, no. 2, (2012).

[3] E. H. Kim, K. B. Kang, J. H. Kim, S. H. Moon, S. B. Oh and S. H. Kim, "Modeling and Analysis of Variable Wind Speed Turbine System Using Back to Back Converter”, Journal of KIIEE, vol. 19, no. 8, (2005).

[4] D. Y. Yu, Y. S. Choi, H. H. Choi and J. W. Jung, "Fuzzy Speed Controller Design of Permanent Magnet Synchronous Generators for Variable-Speed Wind Turbine Systems", Journal of KIIEE, vol. 25, no. 2, (2011).

[5] IEEE Standard 1547.1-2005, "IEEE Standard Conformance Test Procedures for Equipment Interconnecting Distributed Resources with Electric Power Systems", (2005).

[6] IEEE Standard 1547.2-2008, "IEEE Standard for Interconnecting Distributed Resources with Electric Power Systems", IEEE Application Guide for IEEE Std 1547, (2009).

[7] F. D. Mango, M. Liserre, A. D. Aquila and A. Pigazo, "Overview of Anti-Islanding Algorithms for PV Systems. Part I: Passive Methods", IEEE 12th Int. conf. on EPE-PEMC, (2006).

[8] A. Safari, "A Novel Islanding Detection Technique for Distributed Generation (DG) Units in Power System", Int. J. AST, vol. 51, (2013). 
[9] A. Yafaoui, B. Wu and S. Kouro, "Improved Active Frequency Drift Anti-islanding Detection Method for Grid Connected Photovoltaic Systems”, IEEE Trans. on Power Electr, vol. 27, no. 5, (2012).

[10] M. E. Ropp, M. Begovic and A. Rohatgi, "ANALYSIS AND PERFORMANCE ASSESSMENT OF THE ACTIVE FREQUENCY DRIFT METHOD OF ISLANDING PREVENTION", IEEE Trans. on Energy Conv., vol. 14, no. 3, (1999).

[11] G. H. Gonzalez and R. Iravani, "Current Injection for Active Islanding Detection of Electronically-Interfaced Distributed Resources”, IEEE Trans. on Power Deliv, vol. 21, no. 3, (2006).

[12] Y. Zhu, D. Xu, N. He, J. Ma, J. Zhang, Y. Zhang, G. Shen and C. Hu, "A novel RPV (Reactive-PowerVariation) Antiislanding Method Based on Adapted Reactive Power Perturbation", IEEE Trans. on Power Electr, vol. 28, no. 11, (2013).

[13] M. Ciobotaru, R. Teodorescu and F. Blaabjerg, "On-line grid impedance estimation based on harmonic injection for grid-connected PV inverter", IEEE Int. Symposium on Industrial Electr, (2007).

[14] F. Bertling and S. Soter, "A novel converter integrable impedance measuring method for islanding detection in grids with widespread use of decentral generation", Int. Symposium on Power Electr., Electrical Drives, Automation and Motion, (2006).

[15] L. Asiminoaei, R. Teodorescu, F. Blaabjerg and U. Borup, “A Digital Controlled PV-inverter With Grid Impedance Estimation for ENS Detection", IEEE Trans. on Power Electr, vol. 20, no. 6, (2005).

[16] H. M. Oh, S. W. Choi, T. H. Kim, G. P. Lee and T. W. Lee, "Anti-islanding Method by Harmonic Injection for Utility Interactive Inverter with Critical Load", The Trans. of KIPE, vol. 17, no. 4, (2012).

\section{Authors}

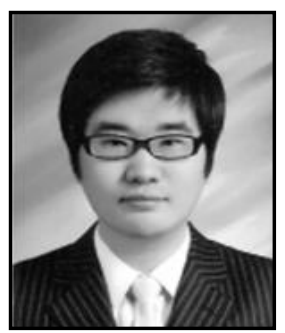

\section{Sung-Wook Kang}

Sung-Wook Kang was born in Gwangmyeong, Korea, in 1988. He received the B.S. degree in electrical engineering from Seoul National University of Science and Technology, Seoul, Korea, in 2013, where he is currently working toward the M.S. degree in the Department of Electrical and Information Engineering. His research interests include three-phase utility interactive inverter, control, fault diagnosis and power electronics.

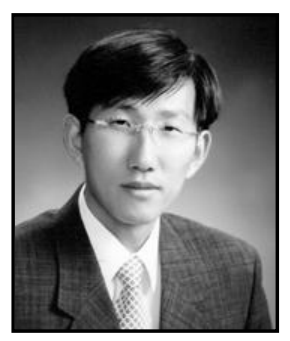

\section{Kyeong-Hwa Kim}

Kyeong-Hwa Kim was born in Seoul, Korea, in 1969. He received the B.S. degree from Hanyang University, Seoul, Korea, and the M.S. and Ph.D. degrees from KAIST, Taejon, Korea, in 1991, 1993, and 1998, respectively, all in electrical engineering. From 1998 to 2000, he was a Research Engineer with Samsung Electronics Company, where he was engaged in research and development of AC machine drive systems. From 2000 to 2002, he was a Research Professor with KAIST. Since August 2002, he has been with Seoul National University of Science and Technology, where he is currently an Associate Professor. His current research interests are in the areas of AC machine drive, control, diagnosis, power electronics, renewable energy, and DSP-based control applications. Prof. Kim is a member of the Korean Institute of Power Electronics (KIPE). 
International Journal of Control Automation Vol. 7, No. 6, (2014) 